\title{
Analysis of Precooling Injection Transient of Steam Generator for High Temperature Gas Cooled Reactor
}

\author{
Yan Wang, Lei Shi, and Yanhua Zheng \\ Institute of Nuclear and New Energy Technology, Tsinghua University, Collaborative Innovation Centre of \\ Advanced Nuclear Energy Technology, Key Laboratory of Advanced Reactor Engineering and Safety, Ministry of Education, \\ Beijing 100084, China \\ Correspondence should be addressed to Yan Wang; wangyanfcw@tsinghua.edu.cn
}

Received 19 December 2016; Revised 8 May 2017; Accepted 23 May 2017; Published 27 July 2017

Academic Editor: Hidemasa Yamano

Copyright (C) 2017 Yan Wang et al. This is an open access article distributed under the Creative Commons Attribution License, which permits unrestricted use, distribution, and reproduction in any medium, provided the original work is properly cited.

\begin{abstract}
After a postulated design basis accident leads high temperature gas cooled reactor to emergency shutdown, steam generator still remains with high temperature level and needs to be cooled down by a precooling before reactor restarts with clearing of fault. For the large difference of coolant temperature between inlet and outlet of steam generator in normal operation, the temperature distribution on the components of steam generator is very complicated. Therefore, the temperature descending rate of the components in steam generator needs to be limited to avoid the potential damage during the precooling stage. In this paper, a pebble-bed high temperature gas cooled reactor is modeled by thermal-hydraulic system analysis code and several postulated precooling injection transients are simulated and compared to evaluate their effects, which will provide support for the precooling design. The analysis results show that enough precooling injection is necessary to satisfy the precooling requirements, and larger mass flow rate of precooling water injection will accelerate the precooling process. The temperature decrease of steam generator is related to the precooling injection scenarios, and the maximal mass flow rate of the precooling injection should be limited to avoid the excessively quick temperature change of the structures in steam generator.
\end{abstract}

\section{Introduction}

Emergency shutdown system will be tripped to start up after a postulated accident is detected, and the decay heat will be removed by the residual heat removal system. Steam generator (SG) still remains with high temperature level after emergency shutdown, and it needs to be cooled down to a certain temperature level before the reactor restarts with faults clearing. In high temperature gas cooled reactor (HTGR), due to the larger temperature difference of coolant between inlet and outlet of SG in normal operation, the temperature distribution on SG is very complicated. Therefore, the temperature descending rate of the SG components during the cooling transient should be controlled to avoid potential damage on the mechanical structure resulting from an excessively quick temperature change.

A precooling design where the SG will be cooled down by a precooling water injection into SG is presented in this paper. Because the mixture of water and steam with high pressure remains in SG after emergency shutdown, it needs to be drained out of SG to decrease the SG pressure for the following cooling water injection into SG. Therefore, the precooling design is composed of two main stages: the first stage defined as pressure relief is the prearrangements including draining the water in SG and decreasing the SG pressure, which will be achieved by the actions of drainingemptier system and pressure relief system. The second stage defined as the precooling water injection is aimed at cooling the SG down with a cooling water injected into the SG. Not only does the SG temperature change obviously during the precooling water injection stage, but also the temperature distribution of the SG structures will also be affected due to heat convection during the pressure relief stage to certain extent. Some relevant discussion on the pressure relief transient could be found in the early study [1], where the effects on the SG temperature under different pressure relief design were compared and the analysis result could provide some support for the pressure relief setting of the current precooling design. 
TABLE 1: Design parameters of HTR-PM.

\begin{tabular}{lc}
\hline Parameters & $\begin{array}{c}\text { Designed } \\
\text { value }\end{array}$ \\
\hline Reactor power $(\mathrm{MWth})$ & $2 \times 250$ \\
Power density $\left(\mathrm{MW} / \mathrm{m}^{3}\right)$ & 3.22 \\
Helium pressure of primary loop $(\mathrm{MPa})$ & 7 \\
Helium mass flow rate $(\mathrm{kg} / \mathrm{s})$ & 96 \\
Inlet helium temperature $\left({ }^{\circ} \mathrm{C}\right)$ & 250 \\
Outlet helium temperature $\left({ }^{\circ} \mathrm{C}\right)$ & 750 \\
Main steam pressure $(\mathrm{MPa})$ & 13.9 \\
Main feedwater temperature $\left({ }^{\circ} \mathrm{C}\right)$ & 205 \\
Main steam temperature $\left({ }^{\circ} \mathrm{C}\right)$ & 571 \\
Feedwater flow rate for one reactor steam generator & 98 \\
$(\mathrm{~kg} / \mathrm{s})$ & \\
\hline
\end{tabular}

In this paper, a further study focuses on the precooling water injection stage to evaluate the precooling design. Several postulated precooling water injections are simulated and compared to evaluate if the precooling water injection designs could cool down the SG to the expected temperature level within the stipulated time and the temperature decrease of SG during the precooling water injection could satisfy the accepted limitation. The high temperature gas cooled reactor pebble-bed module (HTR-PM) is selected for the study on the precooling transient of SG. For better understanding, brief descriptions on the HTR-PM are given in the next section.

\section{The HTR-PM Reactor}

The HTGR as one candidate for the Generation IV nuclear energy system technology [2] is well known with its inherent safety features which has the capability to realize the safety target where the consequences of all conceivable assumed severe accidents should not result in notable offsite radiation impacts [3]. The study on the modular HTGR is developed in China, including the HTR-10 [4] and HTR-PM [5, 6], which consists of $2 \times 250$ MWth module pebble-bed reactor with standardization and modularization technology. The general design parameters on HTR-PM are shown in Table 1.

The single reactor module is illustrated as in Figure 1, which consists of the reactor pressure vessel (RPV), the steam generator pressure vessel (SGPV), and the connecting horizontal coaxial hot-gas duct pressure vessel. The reactor core in the RPV is a one-zone cylindrical loose packed bed with an average height of $11 \mathrm{~m}$ and a diameter of $3 \mathrm{~m}$, which consists of about 420,000 spherical fuel elements in the equilibrium state. The cold helium with an average temperature of $250^{\circ} \mathrm{C}$ is circulated into the RPV through the outer annular channel of the hot-gas duct by the helium blower installed on the top space of the SGPV. The main part of the helium flows upwards to the top of the core through 30 coolant boreholes in the side reflector and is collected in the cold helium plenum located in the upper part of the top reflector, and then it flows down

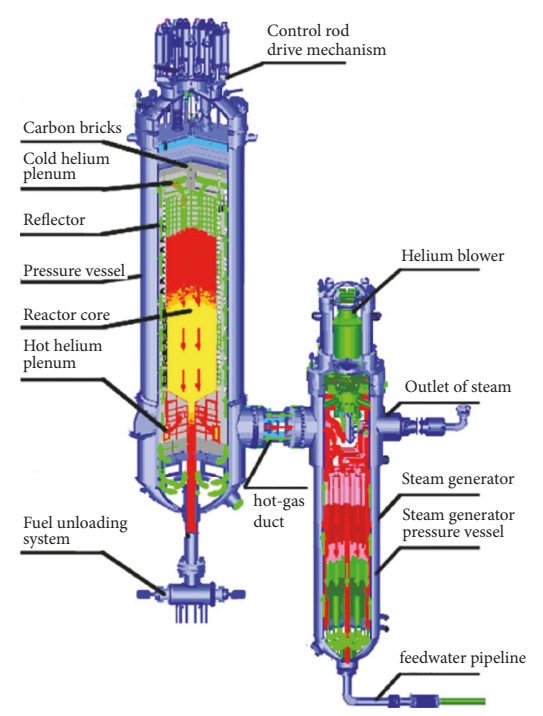

FIgURE 1: Illustration of the HTR-PM.

through the pebble bed and is heated up to an average temperature of $750^{\circ} \mathrm{C}$. The $750^{\circ} \mathrm{C}$ hot helium out of the RPV is fed into the SGPV through the central channel of the hot-gas duct and flows around the outside of the steam generator heatexchange tubes (SGHT) from the upside to the downside to have a heat transfer with the secondary side of the SG. Then, the cooled helium turns reversely at the bottom of the SGPV, flowing upwards between the steam generator shroud and the SGPV and back to the top space of the SGPV.

A simplified schematic diagram of the SG secondary loop of the HTR-PM is illustrated as in Figure 2. The SG is designed as a once-through assembly type of helical tube steam generator placed below the core in elevation. The $205^{\circ} \mathrm{C}$ subcooled feedwater in the secondary side of the SG flows in the helical tubes from the bottom to the top. The $750^{\circ} \mathrm{C}$ hot helium from reactor fed into the SG flows around the SGHT and transfers its heat to the subcooled feedwater in the SGHT to produce a $571^{\circ} \mathrm{C}$ superheated steam at the SG outlet, whereby its temperature decreases from $750^{\circ} \mathrm{C}$ to $250^{\circ} \mathrm{C}$. Then all the superheated steam is collected at the upper plenum and passes through the live-steam pipeline (LP) to the turbine hall. The secondary loop isolation system including the isolation valves on the feedwater pipeline (FP) and the LP is designed to isolate the secondary loop timely after emergency shutdown. To ensure credible isolation, two different feedwater isolation valves (FIV), as well as two main steam isolation valves (SIV), are installed. The drainingemptier system is designed to drain the residual water in the SG after emergency shutdown. An airtight draining storage tank installed inside the reactor building below the SGPV is connected to the FP via two parallel and independent draining pipelines with two draining valves (DV) on each draining pipeline.

\section{Description on the Precooling Injection}

When some postulated accident of HTGR occurs, the reactor safety protection system is tripped to start emergency 


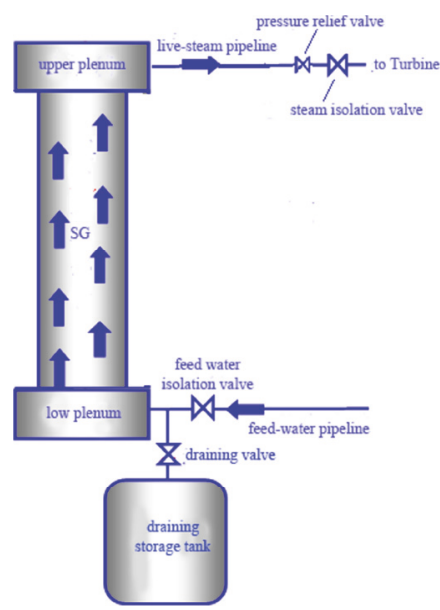

FIGURE 2: Illustration of the HTR-PM secondary loop.

shutdown. A sequence of protective actions is carried out, including dropping of all reflector rods, shutdown of blower and close of blower flaps, and isolation of the SG secondary side. SG which remains with high temperature level after emergency shutdown will be cooled down by the precooling. In this paper, a postulated precooling solution is proposed to study. A series of actions will be carried out as the following: the water in SG will be discharged by the draining-emptier system, and the pressure relief valve (PRV) installed on the LP will be opened to decrease the secondary side pressure of the SG for the precooling injection. Then, the precooling water in the form of superheated steam is pumped into the secondary side of the SG to cool down the SG.

The SGHT has a very complicated temperature distribution, whose minimal temperature is less than $250^{\circ} \mathrm{C}$ and maximal temperature exceeds $570^{\circ} \mathrm{C}$ in the normal steadystate operation. During the water-discharge and the pressure relief, the mixture of water and steam in the secondary side of the SG will flow through the SGHT and the LP and transfer heat with them; thus, the temperature distribution of the structures will be affected, whose effect had been analyzed in the early study $[1,7]$. With the following precooling water injection, the SGHT and the LP will be cooled down and the temperature decrease during the transient will have a stress effect on the structures. The excessive change of temperature which may result in the potential damage should be avoided. Therefore, the study on the precooling injection is significant for HTGR and it will be focused in the following sections.

\section{Analysis of the Precooling Injection Transient}

4.1. Analysis Model. A system code PCNHR developed by Tsinghua University and used for transient thermal-hydraulic analysis of flow systems is used to simulate the precooling transient. The PCNHR [8] code had been benchmarked by the comparison with the famous general analysis code of RETRAN-02 [9], which is widely used in the plant design for pressurized water reactor (PWR).

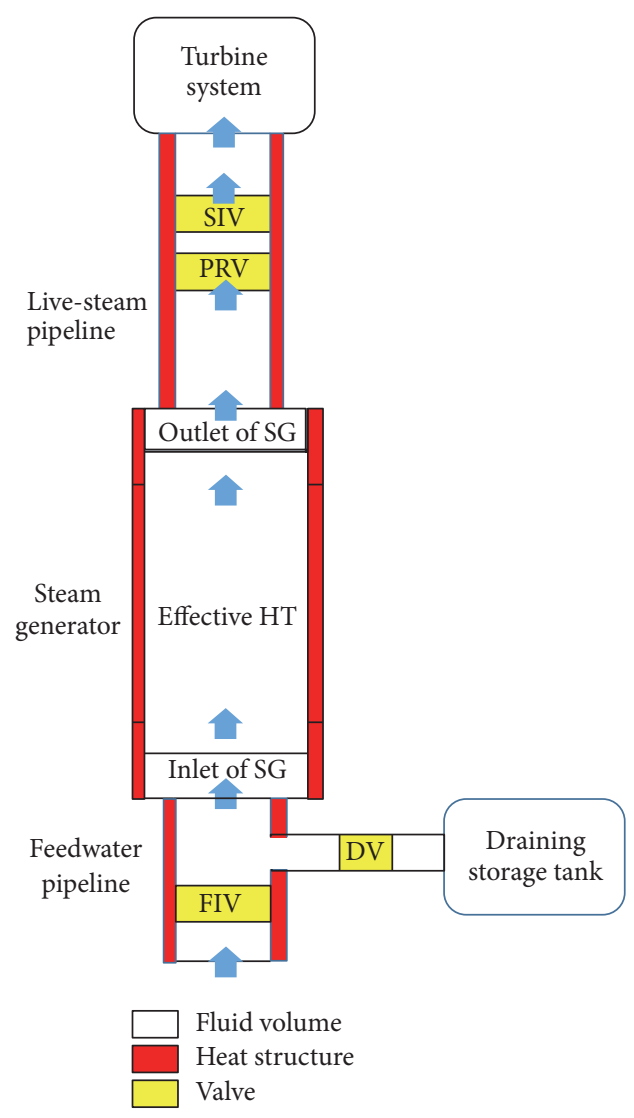

FIGURE 3: Secondary loop model of the HTR-PM.

The analysis model for the secondary loop of the HTR$\mathrm{PM}$ is shown as in Figure 3.

The secondary loop of HTR-PM consists mainly of the FP, the SGHT, and the LP. The SGHT bundles are simplified as one pipe with equivalent thermal-hydraulic diameter in the model. It includes the inlet part, the outlet part, and the effective heat transfer part which transfers heat between the primary side and the secondary side, and the total SGHT is divided into 72 meshes in its length direction. The FP is divided into 2 meshes in length direction and the LP is divided into 54 meshes in length direction. The DV on the draining pipeline, the FIV on the FP, and the PRV and the SIV on the LP are all represented by control function in the model. The components, such as the SGHT, the FP, and the LP, are modeled with "heat structure" in the model, whose temperature is affected by heat transfer between the wall surface of the components and the fluid in the secondary loop during the transient. Because the helium circulation in the primary loop stops after emergency shutdown, the heat transfer from the primary side of SG to the secondary side through the SGHT by heat conduction and natural convection is weak. Therefore, the outside wall surface of the SGHT is assumed as adiabatic boundary in model. The outside wall surfaces of the FP and the LP are also treated as adiabatic boundary for the heat insulating material wrapped outside them.

The precooling fluid is injected from the LP as input source and transfers heat with the "heat structures" when it 
passed through the SG. The heat transfer coefficient correlation will be automatically chosen in the code according to flow condition. In this code, Dittus-Boelter correlation is used for forced convection heat transfer with single-phase vapor flow.

$$
\mathrm{Nu}=0.023 \mathrm{Re}^{0.8} * \operatorname{Pr}^{0.4}
$$

where $\mathrm{Nu}$ is Nusselt number, Re is Reynolds number, and $\mathrm{Pr}$ is Prandtl number.

4.2. Assumptions and Claims. For the operation of nuclear power plant with higher efficiency, the SG is expected to be cooled down as soon as possible. On the other side, the temperature descending rate of SG during the precooling transient must be controlled below the acceptable limitation to avoid potential damage on the mechanical structure from an excessively quick temperature change. In this analysis, the SG is required to be cooled down to $200^{\circ} \mathrm{C}$ within 8 hours by the precooling injection for the next actions of reactor system. According to a conservative stress evaluation on the SG components, the limitation on the maximal temperature descending rate of SG components during the cooling transient is defined as $3^{\circ} \mathrm{C} / \mathrm{min}$ in this analysis.

A postulated scenario is defined in this analysis: the reactor in normal operation is led to emergency shutdown for some certain reason; a sequence of protection actions are triggered. After the protection actions are completed, the PRV is opened to control the pressure decrease of the secondary side to approx. $1 \mathrm{MPa}$. Then, the precooling water is injected into the secondary side of the SG to cool down the components. The superheated steam injection is designed to avoid sudden cold shock from phase transition of fluid during the transient, and the support system for precooling injection could supply a stable steam below $200^{\circ} \mathrm{C}$. Therefore, several postulated precooling injection cases are designed and compared to study their effect on the components during the transient.

Case 1. It includes a $200^{\circ} \mathrm{C} / 1.1 \mathrm{MPa}$ precooling injection with a constant mass flow rate of $1 \mathrm{t} / \mathrm{h}$.

Case 2. It includes a $200^{\circ} \mathrm{C} / 1.1 \mathrm{MPa}$ precooling injection with a constant mass flow rate of $5 \mathrm{t} / \mathrm{h}$.

Case 3. It includes a $200^{\circ} \mathrm{C} / 1.1 \mathrm{MPa}$ precooling injection with a variable mass flow rate as shown in Figure 4.

Case 4. It includes a variable precooling steam injection as shown in Table 2.

The larger the mass flow rate of precooling injection, the faster the cooling of steam generator. Also because of more and more uniform temperature distribution on the SG components with continuous precooling injection, the transient could be accelerated by increasing the mass flow rate of precooling injection and decreasing the temperature of precooling fluid. However, the precooling injection with constant mass flow rate and temperature has better feasibility for the real precooling system design than that with variable mass flow rate and temperature. Hence, an expected

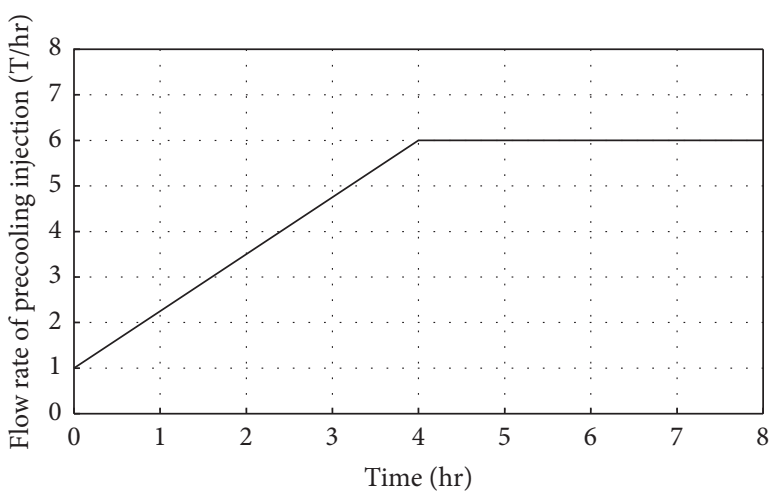

Figure 4: Mass flow rates of Case 3.

TABLE 2: Precooling injection in Case 4.

\begin{tabular}{lccc}
\hline Time $(\mathrm{hr})^{*}$ & Flow rate $(\mathrm{T} / \mathrm{hr})$ & Temperature $\left({ }^{\circ} \mathrm{C}\right)$ & Pressure $(\mathrm{MPa})$ \\
\hline $0-2$ & 1 & 190 & 1.1 \\
$2-4$ & 4 & 170 & 0.7 \\
$4-6$ & 6 & 170 & 0.7 \\
$6-8$ & 6 & 150 & 0.3 \\
\hline
\end{tabular}

${ }^{*}$ The time is calculated from the beginning of the precooling injection.

precooling design should have a good balance of the cooling effect and the feasibility of the design. In this analysis, by comparison with Cases 1 and 2, the cooling effect is studied for the precooling design with constant mass flow rate in the range from $1 \mathrm{t} / \mathrm{h}$ to $5 \mathrm{t} / \mathrm{h}$, and Cases 3 and 4 with variable flow rate and temperature are designed for the study on the acceleration of the precooling.

4.3. Analysis Results. The fluid temperatures at different locations with different cooling water injections are shown in Figure 5. The results show that, under the case with $1 \mathrm{t} / \mathrm{h}$ precooling water injection, the fluid temperature at the SGHT outlet is approx. $345^{\circ} \mathrm{C}$ at the 8 th hour after the precooling injection, while the fluid temperature at the PRV in the LP is about $400^{\circ} \mathrm{C}$. In Case 2 with $5 \mathrm{t} / \mathrm{h}$ precooling water injection, both of the fluid temperatures at the SGHT outlet and at the PRV decrease to $200^{\circ} \mathrm{C}$ within 5 hours, which indicates that the SGHT and the LP had been well cooled down by the precooling water injection.

The wall temperatures of the SGHT at the outlet and the LP at the PRV under different cooling water injections are shown in Figure 6. The wall temperature at the SG outlet descends to approx. $347^{\circ} \mathrm{C}$ in 8 hours in Case 1; meanwhile, the wall temperature at the PRV is $408^{\circ} \mathrm{C}$. But in the case with $5 \mathrm{t} / \mathrm{h}$ precooling water injection, the wall temperature of the SGHT and the LP had almost decreased to $200^{\circ} \mathrm{C}$ in 5 hours. The SGHT and the LP are also cooled down to $200^{\circ} \mathrm{C}$ in Case 3 , although it needs more time than that in Case 2. In Case 4, the SGHT and the LP are cooled down below $200^{\circ} \mathrm{C}$ within 6 hours; then their temperatures decrease continuously with the temperature decrease of the precooling water.

Figure 7 shows the temperature distribution of the SGHT and the LP at different time points. The total length of the SGHT and the LP is normalized and the SGHT inlet is 


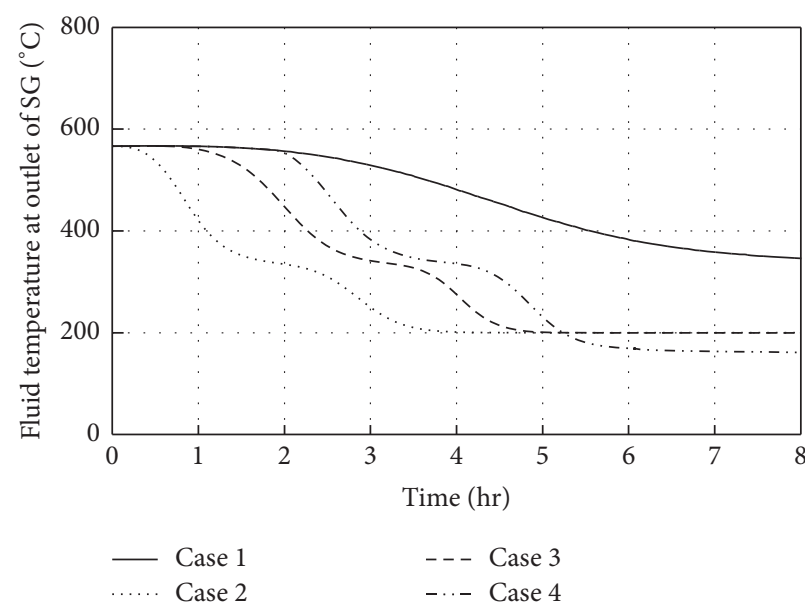

(a)

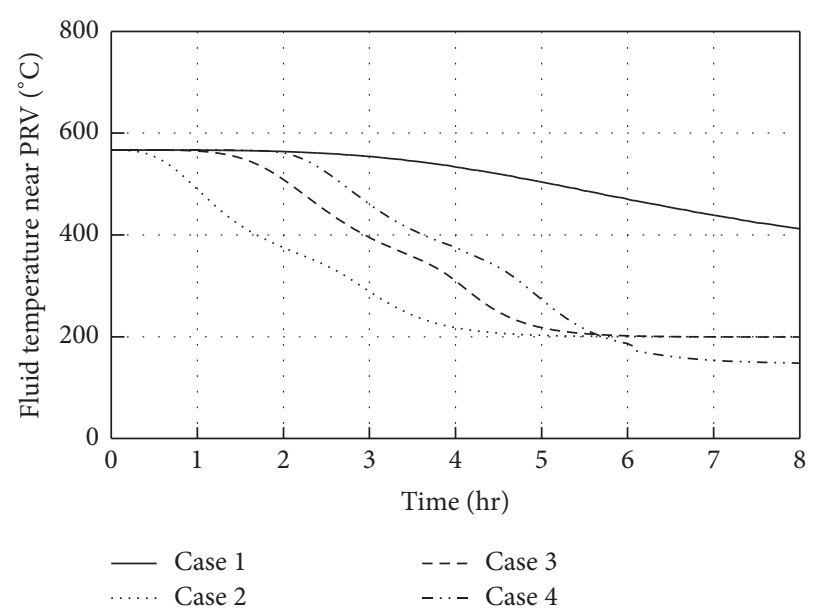

(b)

FIGURE 5: Fluid temperature at different locations during precooling injection.

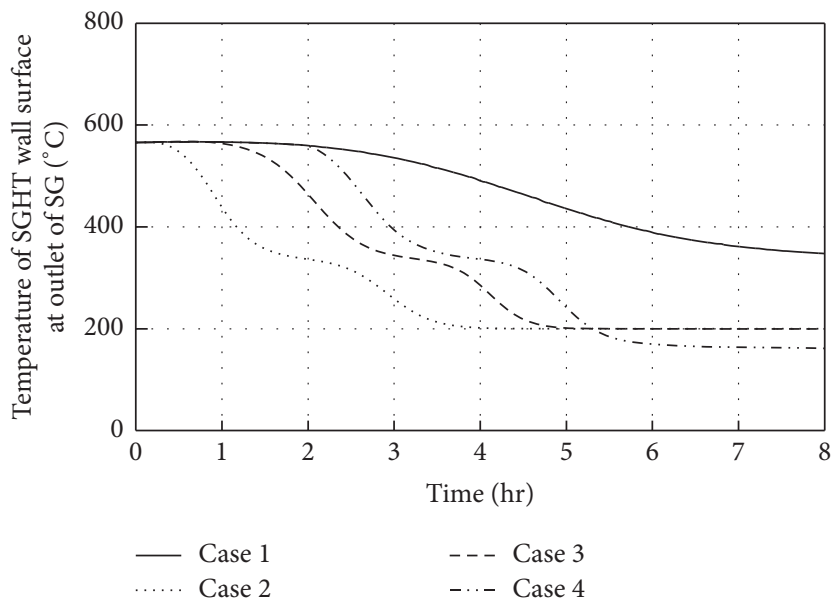

(a)

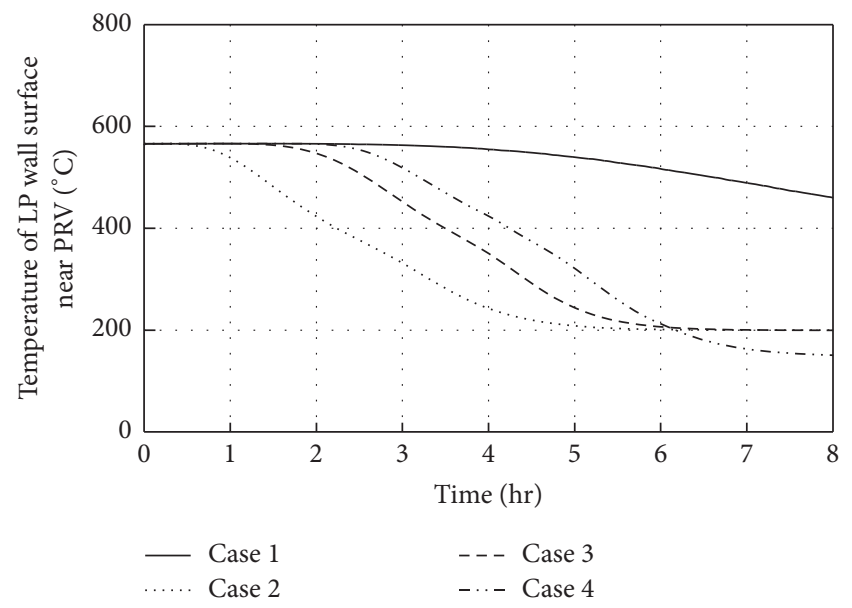

(b)

FIgURE 6: Wall surface temperature at different locations during precooling injection.

set as the start point. It is observed that the temperature distribution on the SGHT is uneven before the precooling water injection and its temperature decreases continuously with the precooling water injection. In both Cases 3 and 4 , the SGHT and the LP could be cooled down to $200^{\circ} \mathrm{C}$ in 6 hours after the precooling injection. Larger flow rate of the precooling water injection will accelerate the transient, and the precooling process will finish in 5 hours under the case with $5 \mathrm{t} / \mathrm{h}$ precooling injection. But the maximal wall temperature still remains above $400^{\circ} \mathrm{C}$ after 8 hours of the precooling injection under Case 1 , which indicates that the $1 \mathrm{t} / \mathrm{h}$ precooling injection is not enough to satisfy the precooling requirements.

The temperature descending rates at some typical locations of the SGHT during the transient are shown in Figure 8. The temperature descending rate of the SGHT in Case 2 is obviously higher than that in other cases at the early stage of the precooling injection, which indicates that higher flow rate of the precooling injection results in faster temperature decrease. Although the precooling transient could be accelerated by flow rate increase or temperature decrease of the precooling injection for more uniform temperature distribution on the SGHT with continuous precooling, the temperature descending rate at the outlet of SGHT in Case 4 exceeds $3^{\circ} \mathrm{C} / \mathrm{min}$ after 2 hours, which indicates that the flow rate increase of the precooling injection in Case 4 is a little faster than the limitation. The location where the maximal descending rate of SGHT temperature occurs during the transient is also related to the precooling injection scenario; the maximal descending rate of SGHT occurs at the inlet of SGHT in Case 1 , while it occurs at the outlet of SGHT in Case 3.

4.4. Comparison Results. With the above results, it can be known that the SG in Cases 2-4 can be cooled down to the expected temperature level in 8 hours but Case 1 cannot satisfy the requirement. In the other side, the maximal temperature descending rates in Cases 1 and 3 are controlled below $3^{\circ} \mathrm{C} / \mathrm{min}$, but those in Cases 2 and 4 exceed the 


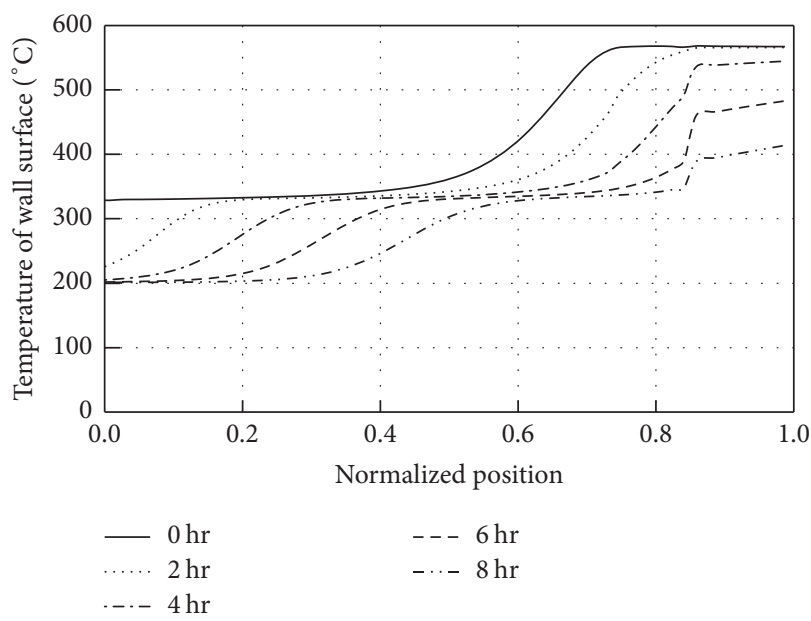

(a)

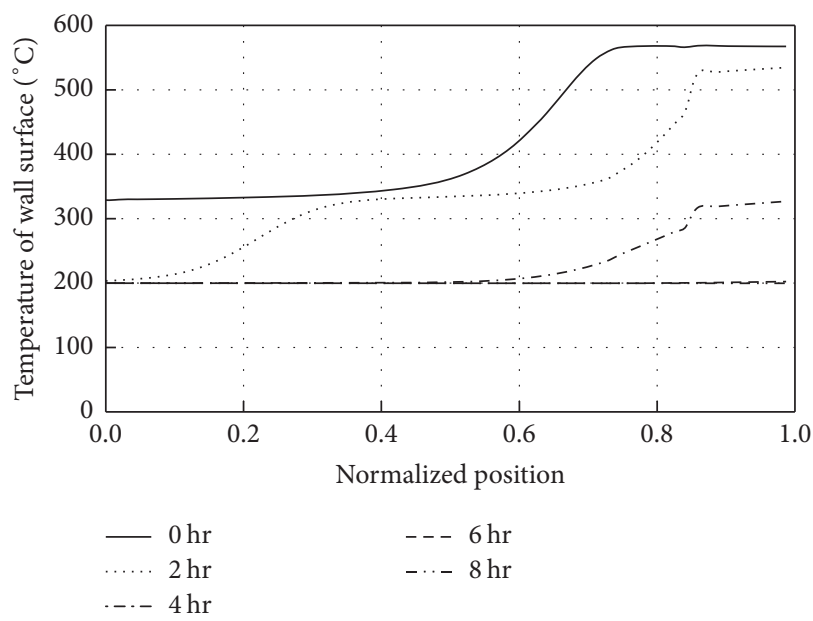

(c)

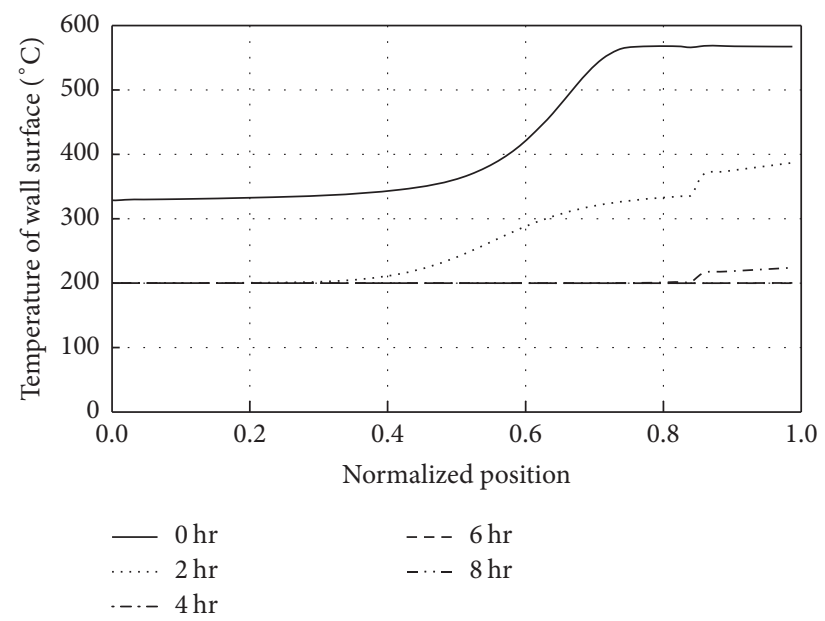

(b)

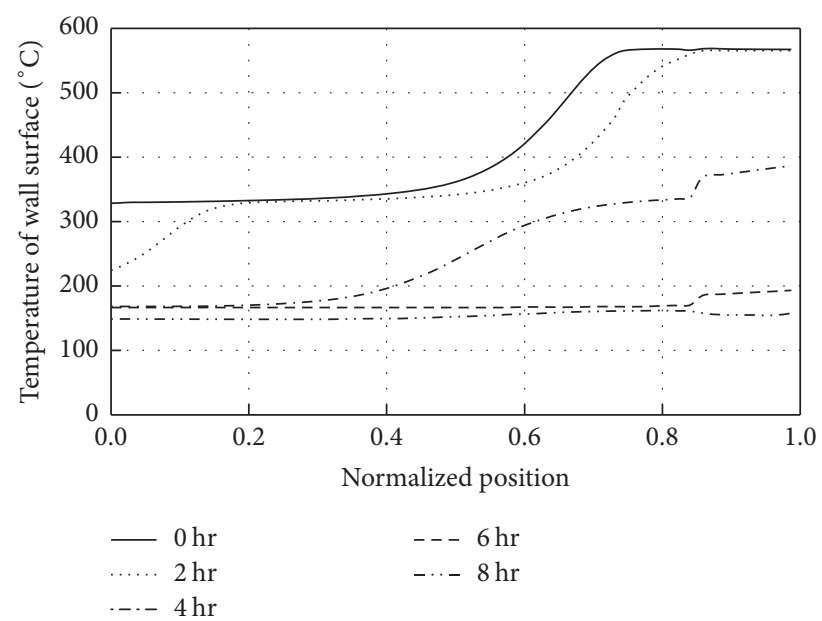

(d)

FIGURE 7: Temperature distribution of SGHT and LP during precooling injection.

limitation. Therefore, it can be concluded that Case 3 is better in all the current provided precooling cases. Because the SG in Case 3 has been cooled down to $200^{\circ} \mathrm{C}$ only within 6 hours, the temperature descending rate could be decreased further by decreasing the flow rate of the precooling injection.

\section{Conclusions}

A precooling injection is needed to cool down the steam generator, which remains with high pressure and high temperature level after emergency shutdown of high temperature gas cooled reactor. Larger mass flow rate of precooling water injection will accelerate the precooling process, but the temperature descending rate of the structures should also be limited to avoid the potential damage on the components from excessively quick temperate change. Some different precooling injection scenarios for a 200 MWe high temperature gas cooled reactor are analyzed and compared. The analysis results show that enough precooling water injection is necessary for the cooling of steam generator to satisfy the precooling target in the stipulated time. The time when the maximal temperature descending rate of SGHT occurs and the location where the maximal temperature descending rate of SGHT occurs are related to the precooling injection scenario. Based on the analysis result of the HTR-PM, it is concluded that the SG could be cooled down to the expected temperature level with a reasonable precooling injection. For the reason that the temperature distributions of the SGHT get more uniform with the continuous precooling injection, the precooling transient could be accelerated by gradually increasing the flow rate of the precooling injection.

\section{Initialisms}

DV: Draining valve

FIV: Feedwater isolation valve

FP: $\quad$ Feedwater pipeline

HTGR: High temperature gas cooled reactor

LP: Live-steam pipeline

PRV: Pressure relief valve 


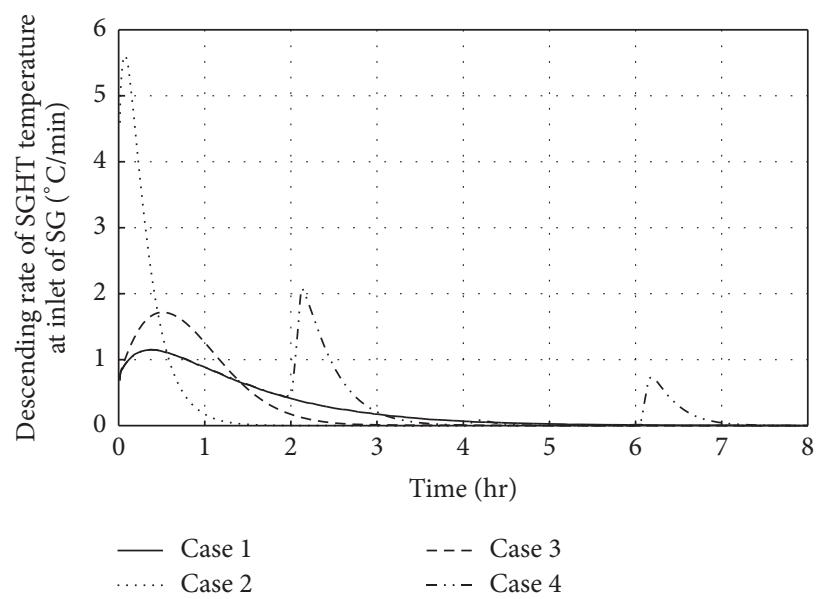

(a)

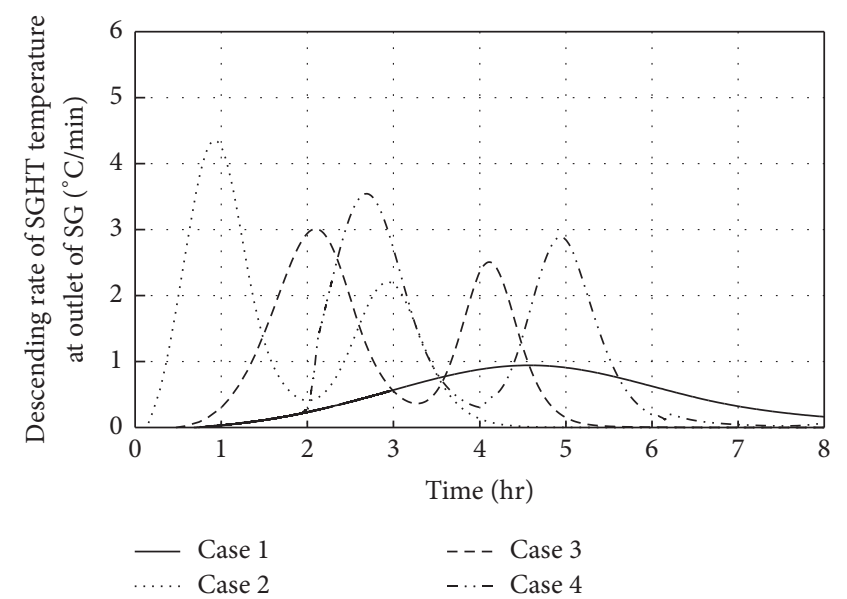

(c)

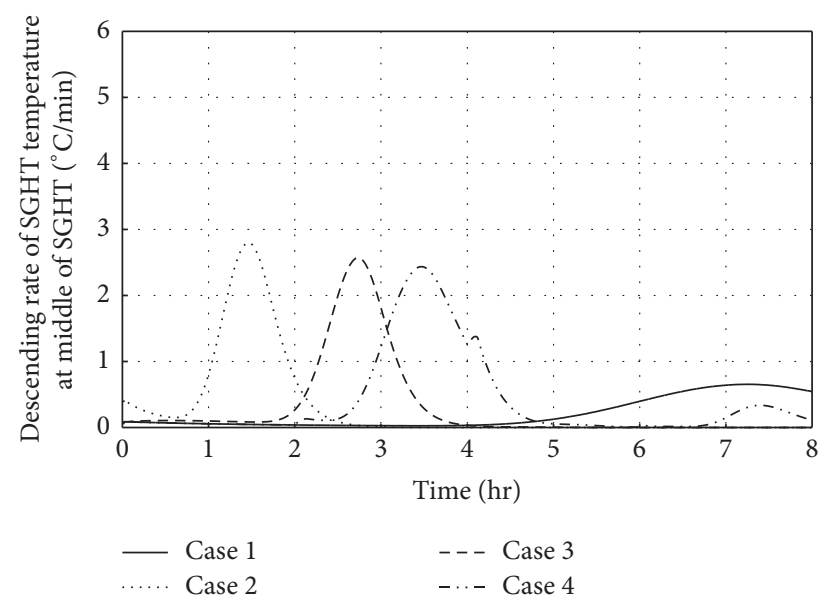

(b)

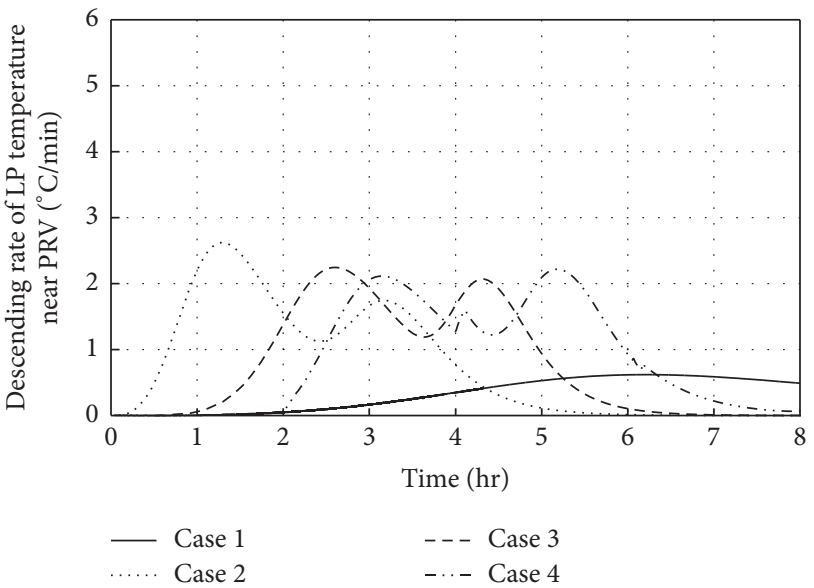

(d)

FIgURE 8: Temperature descending rate at different locations during precooling injection.

RPV: Reactor pressure vessel

SG: $\quad$ Steam generator

SGHT: Steam generator heat-exchange tubes

SGPV: Steam generator pressure vessel

SIV: Steam isolation valves.

\section{Conflicts of Interest}

The authors declare that they have no conflicts of interest.

\section{Acknowledgments}

This work was supported by the National Science and Technology Major Project (no. ZX06908) and the National High Technology Research and Development Program of China (863) (2014AA052701).

\section{References}

[1] W. Yan, "Study on pressure relief system design for high temperature gas cooled reactor," Progress in Nuclear Energy, vol. 77, pp. 344-351, 2014.
[2] M. A. Fütterer, L. Fu, C. Sink et al., "Status of the very high temperature reactor system," Progress in Nuclear Energy, vol. 77, pp. 266-281, 2014.

[3] G. H. Lohnert, "Technical design features and essential safetyrelated properties of the HTR-module," Nuclear Engineering and Design, vol. 121, no. 2, pp. 259-275, 1990.

[4] Y. Xu and K. Zuo, "Overview of the $10 \mathrm{MW}$ high temperature gas cooled reactor - Test module project," Nuclear Engineering and Design, vol. 218, no. 1-3, pp. 13-23, 2002.

[5] Z. Zhang, Z. Wu, Y. Sun, and F. Li, "Design aspects of the Chinese modular high-temperature gas-cooled reactor HTRPM," Nuclear Engineering and Design, vol. 236, no. 5-6, pp. 485490, 2006.

[6] Z. Zhang, Y. Dong, F. Li et al., "The Shandong Shidao Bay 200 MWe high-temperature gas-cooled reactor pebble-bed module (HTR-PM) demonstration power plant: an engineering and technological innovation," Engineering, vol. 2, no. 1, pp. 112-118, 2016.

[7] Y. Wang, "Study on Pressure Relief Transient for High Temperature Gas Cooled Reactor," in Proceedings of the 2012 20th International Conference on Nuclear Engineering and the ASME 2012 Power, p. 269, Anaheim, Calif, USA. 
[8] J. Liu, Z. Zhang, D. Lu, Z. Shi, X. Chen, and Y. Dong, "Personal computer-based simulator for nuclear-heating reactors," Nuclear Technology, vol. 129, no. 2, pp. 175-186, 2000.

[9] Anon, "RETRAN02-A Program for Transient Thermal Hydraulic Analysis of Complex Fluid Flow Systems," Electric Power Research Institute (Report) EPRI NP, vol. 1, 1981. 


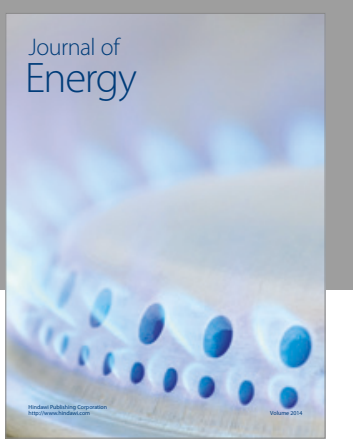

Journal of

Industrial Engineering
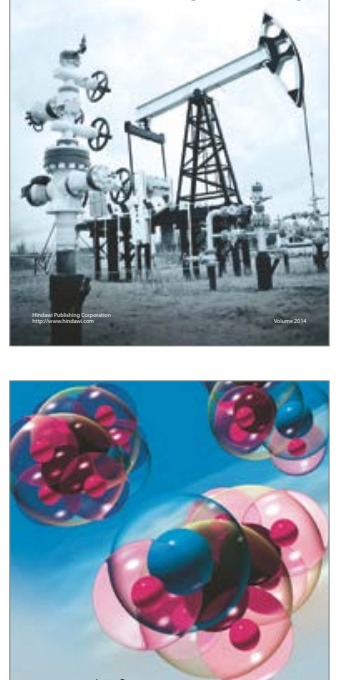

Fuels
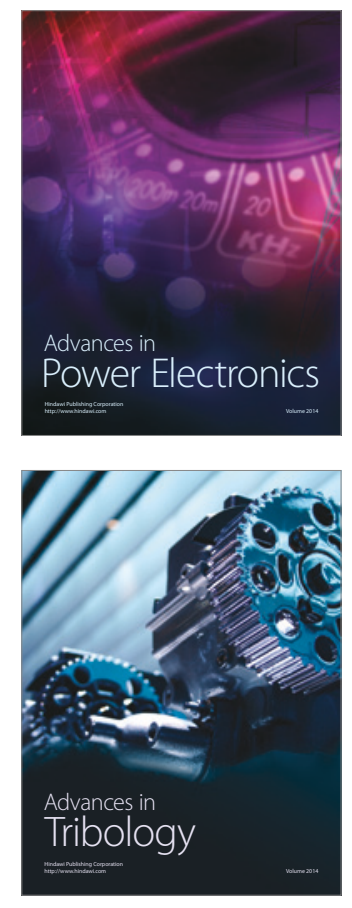
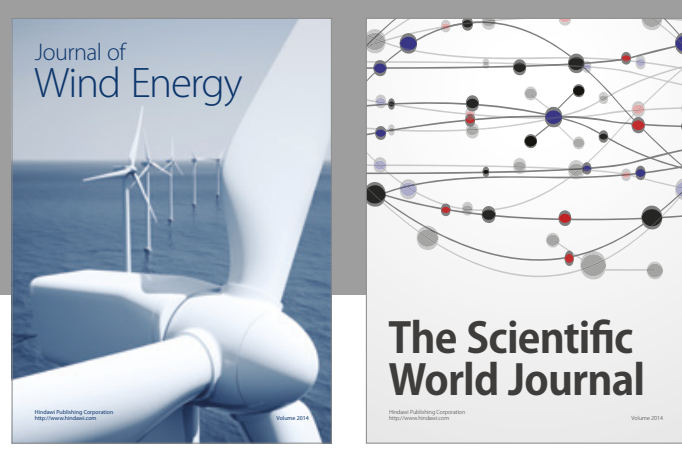

The Scientific World Journal
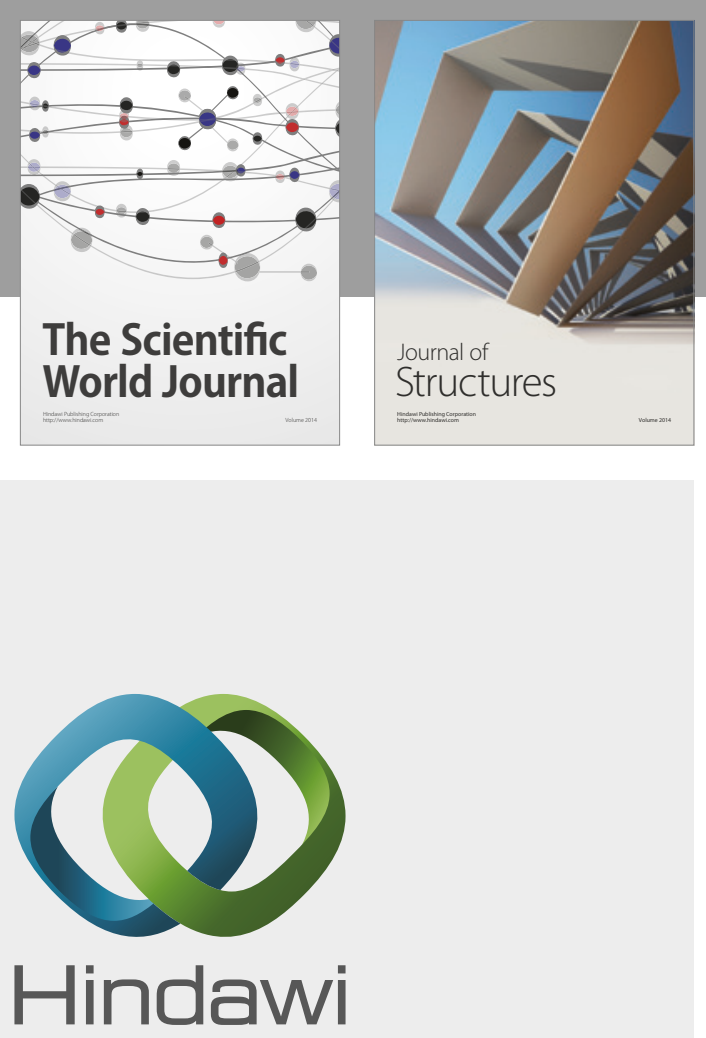

Submit your manuscripts at

https://www.hindawi.com
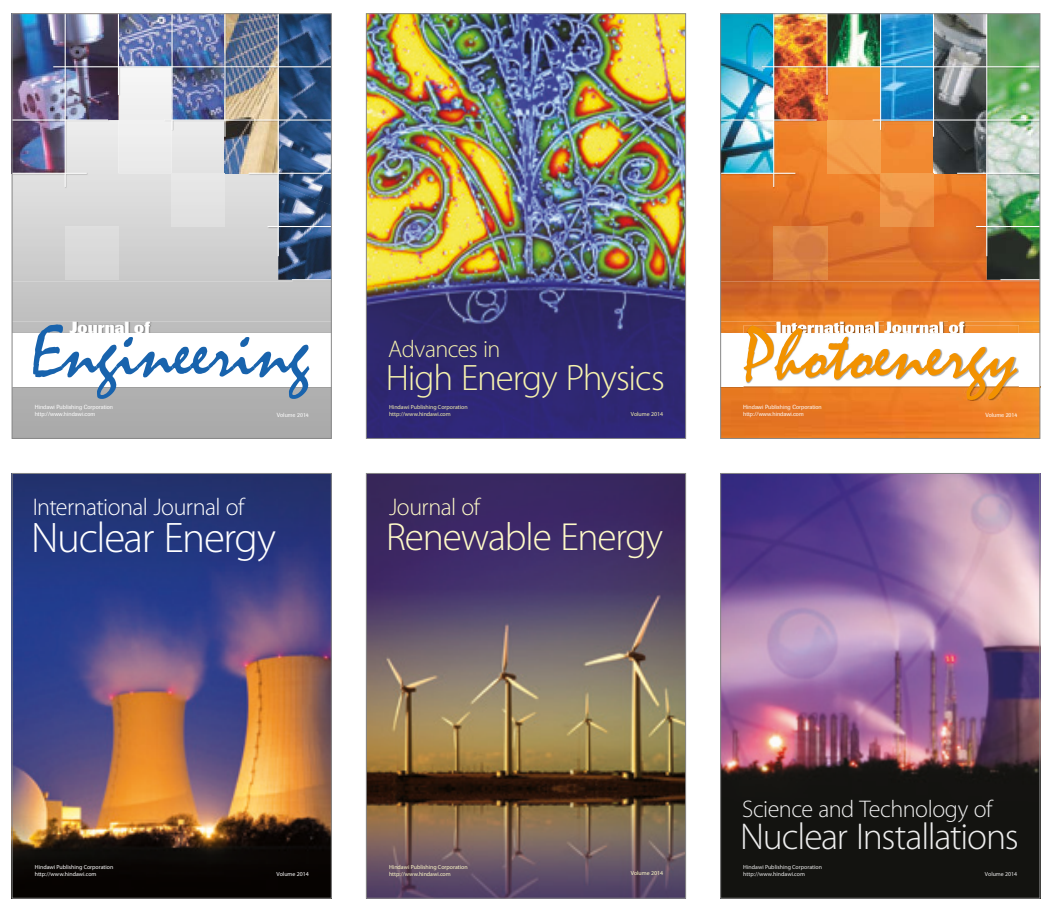

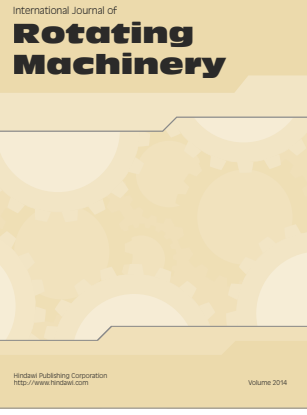

Journal of

Petroleum Engineering

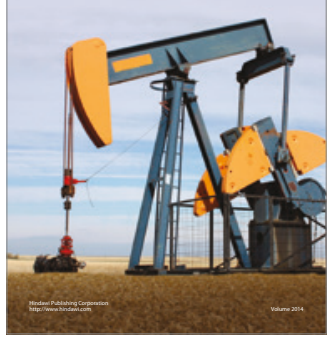

Journal of
Solar Energy
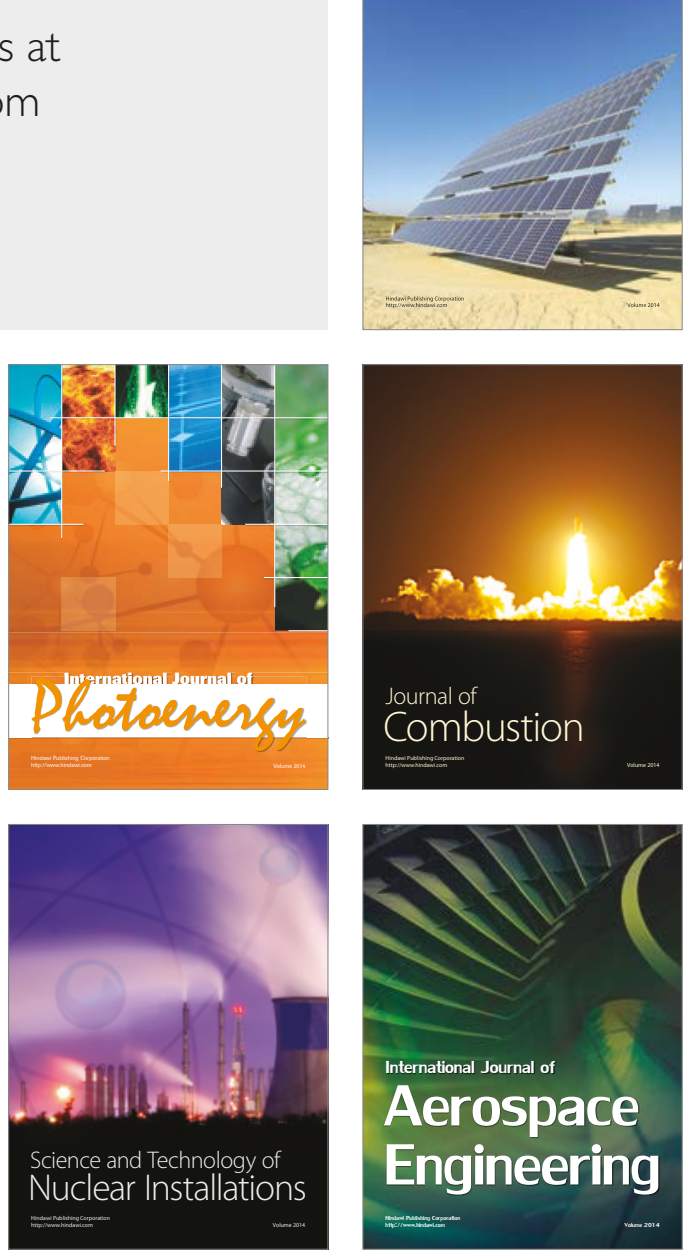